\title{
Lígia Bellini. A coisa obscura: mulher, sodomia e inquisição no Brasil colonial. Salvador: EDUFBA, 2014, 113 pp.
}

\author{
Mariana Meneses Muñoz *
}

$\mathrm{L}$ a reconstrucción de la vida privada en las sociedades del Antiguo Régimen ha supuesto un desafio para los investigadores. Las fronteras entre lo público y lo privado eran difusas, y las prácticas propias del ámbito de lo privado se presentaban sin que sus espacios estuvieran claramente definidos. En ocasiones lo privado se reservaba para contextos que no eran susceptibles de documentar; por lo tanto, leer entre líneas y rastrear cualquier vestigio de las expresiones individuales o colectivas es fundamental al momento de abordar la vida privada y cotidiana de la época.

A lo largo de las décadas de 1980 y 1990 se estaba fortaleciendo en Brasil una vertiente que estudiaba los aspectos de la vida privada y cotidiana —alejada cada vez más de las tendencias de corte estructuralista y marxista-, en relación con las instituciones de poder que buscaban regular los aspectos más íntimos de los habitantes del Brasil colonial. La vida privada en la América portuguesa no podía abordarse de la misma manera que en Europa, puesto que esta colonia tenía particularidades, sujetos y espacios que respondían a las lógicas del contexto específico y para su análisis se precisaba la ayuda de otras disciplinas como la antropología y la sociología. Dentro de los trabajos influenciados por la escuela de los Annales y su Nueva Historia, que abordaron los tradicionales estudios sobre inquisición a la luz de los comportamientos que iban más allá de los procesos por judaísmo, se concibieron las tesis de investigadores como Luiz Mott, Ronaldo Vainfas, Laura de Mello e Souza y Lígia Bellini. Precisamente, en A coisa obscura (1989), producto de su tesis de maestría en Historia realizada en la Universidade Federeal da Bahia en 1987, Bellini analiza los casos de relaciones sexuales y afectivas entre las mujeres del nordeste brasileño que fueron considerados como sodomía femenina en las visitas del Tribunal del Santo Oficio de Portugal durante los siglos XVI y XVII.

A coisa obscura plantea cómo las concepciones de los comportamientos de tipo sexual entre las mujeres que contravenían las leyes y moral durante la formación de moralidades en el Brasil colonial, fueron influenciadas por el

* Estudiante de la Maestría en Historia, Universidad Nacional de Colombia, sede Medellín. 
pensamiento europeo renacentista a partir de la religión, las leyes civiles y el conocimiento médico. Apoyada en los documentos hallados en el Arquivo da Torre do Tombo relativos a la primera y segunda visitação y los procesos de sodomía seguidos por la Inquisición portuguesa — casos recurrentes en las investigaciones sobre el tema debido a la escasez de procesos existentes en los archivos-, disposiciones del Santo Oficio, leyes seculares, prescripciones eclesiásticas y manuales de confesión, la autora logra construir una genealogía de la concepción del mundo homoerótico femenino para los siglos XVI y XVII, así como el panorama discursivo que normatizaba las diferentes formas de relacionamiento de tipo sexual en el ámbito privado desde la visión "sesgada" de la Iglesia y el Estado. Dentro de estas referencias se debe resaltar el tratado de Luigi-Maria Sinistrari, De Sodomia, ya que es un texto central en el trabajo, particularmente en los apartados "Taxonomia" y "A coisa obscura", en los cuales se trata la forma de la sodomía femenina y los discursos morales y médicos que se mezclaban para explicarla y condenarla. Bellini también presenta un análisis del lenguaje a través del cual se intentó entender y dar lugar en la legislación a las relaciones homoeróticas femeninas durante el Renacimiento y la Edad Moderna, una práctica que se suponía exclusiva del sexo masculino y que, por ende, se basaba en el reconocimiento y anatomía del hombre. La confusión taxonómica que se presentaba en torno a la sodomía femenina logra verse plasmada en el lenguaje indefinido y velado con el que se trataba en los documentos y la legislación. Asimismo, la autora se remite a las teorías aristotélicas con el fin de mostrar la imagen de inferioridad de la mujer que se construyó en la Antigüedad y cómo esta permaneció en el tiempo.

Al establecer una clasificación de las mujeres involucradas en los casos de sodomía, Bellini muestra los diversos grupos sociales o castas que interactuaban en Brasil. A través de la procedencia, el estado civil, la edad al cometer la falta y la pena que se le había dado, evidencia algunas características claves para comprender las formas en las que las autoridades tanto civiles como eclesiásticas concebían y juzgaban a los sujetos según su procedencia y el cumplimiento de las fórmulas dadas por las leyes civiles e inquisitoriales (quién, cuándo, cómo). Con esta clasificación la autora establece la presencia de varias mujeres portuguesas dentro de los procesos, algunas incluso reincidentes en su falta y desterradas a Brasil por haber cometido sodomía con otra mujer, lo que demuestra que esta no era una práctica originaria del Nuevo Mundo.

En la reciente reedición de la Editora da Universidade Federal da Bahia (EDUFBA), Bellini recoge nueva bibliografia sobre sexualidad en el mundo moderno, en particular de la historiografia anglosajona, que influye y matiza la forma de presentar la investigación. Además, retoma los conceptos, teorías y términos de las tradiciones intelectuales de la Nueva Historia, en especial autores de Francia y del Reino Unido, así como corrientes historiográficas de Estados Unidos y Brasil acerca de las identidades sexuales y la vida privada y cotidiana para argumentar las diversas visiones que existían sobre la sexualidad femenina y los comportamientos homoeróticos que le sirvieron para reconstruir a los sujetos con identidades 
sexuales que contravenían el orden social. Estos referentes conceptuales muestran no solo los diversos estudios que se han realizado sobre el tema, sino las nociones que existieron sobre la mujer y su papel jurídico y social durante la Antigüedad, así como su revalidación y transformación en el tiempo, en especial durante el Antiguo Régimen. La autora también explica la relación entre Inquisición y sociedad, las dinámicas sociales que se dieron durante las visitas y procesos del Santo Oficio, el papel moralizador y las lógicas "pedagógicas" de los actos punitivos de esta institución en el Brasil colonial.

Es preciso señalar la ausencia de textos de la academia hispanoamericana sobre el tema en la bibliografía, la cual apunta a tres aspectos: el primero tiene que ver con la carencia de estudios sobre sexualidad y vida privada en Hispanoamérica. Solo en las últimas tres décadas comienza a darse una corriente investigativa sobre el tema, con la publicación de los trabajos compilatorios: Historia de la vida privada en Argentina (1999), Historia de la vida cotidiana en México (2004 y 2005), e Historia de la vida privada en Colombia (2011). El segundo tiene que ver con la limitada producción de textos relacionados con el entorno social y cultural de las inquisiciones latinoamericanas - México, Cartagena de Indias y Lima-, su falta de divulgación y el papel secundario que se le ha dado dentro de la enseñanza de la historia. Por último, está el poco intercambio que ha existido entre la academia hispanoamericana y la brasilera, aunque esta cuestión ha ido cambiando durante los últimos diez años, en esta edición persiste la omisión de la producción hispanoamericana sobre el tema.

Para terminar, es importante mencionar la relevancia de $A$ coisa obscura dentro de la historiografia brasilera y el estudio de la vida privada del Brasil colonial. A pesar de haber sido publicada hace veintinueve años, la investigación realizada por Lígia Bellini ha sido remozada y sigue teniendo vigencia en la historiografia lusófona sobre la historia de la sexualidad, los estudios culturales sobre la mujer, la vida privada y las minorías sociales en Brasil. Este trabajo hace parte del grupo de investigaciones que en la década de 1980 incursionó en la producción historiográfica sobre las mentalidades desde la relación entre moralidades, sexualidad y el Santo Oficio, y evidenció los procesos de aculturación y mestizaje moral y cultural de los sujetos que habitaban esta posesión portuguesa. Las fuentes documentales que aborda el libro, su bibliografia, así como las formas de utilización de los documentos de archivo son un ejemplo de las diversas maneras de hacer historia sobre los grupos subalternos y sus prácticas, ya que trabaja con sujetos o grupos sociales de los que es difícil encontrar grandes huellas en el mundo escrito, por lo que tradicionalmente ocupaban un segundo plano en los estudios sobre las sociedades antigua, renacentista y moderna.

DOI: 10.17533/udea.trahs.n11a10 